\title{
Esquerda e direita no sistema partidário brasileiro: análise de conteúdo de documentos programáticos
}

Left and Right in the Brazilian party system: content analysis of programmatic documents

\section{Gabriela da Silva Tarouco Rafael Machado Madeira}

\section{Resumo}

A ideologia dos partidos políticos brasileiros, recorrentemente apontada como inconsistente, é neste artigo mensurada a partir da análise de conteúdo dos seus documentos programáticos, a partir de uma escala alternativa, elaborada para captar especificidades brasileiras, geralmente negligenciadas na literatura comparada internacional. As posições dos sete principais partidos brasileiros são calculadas na dimensão esquerda-direita e na dimensão conservador-liberal, que são em seguida cruzadas para a formação de um plano bidimensional. Os resultados encontrados são comparados a outras classificações encontradas na literatura sobre o Brasil e indicam a pertinência de mobilizar a posição ideológica dos partidos como variável independente para a compreensão de diversos aspectos do sistema partidário brasileiro.

\section{Palavras-chave}

Partidos Políticos; Ideologia; Análise de Conteúdo; Manifestos Partidários.

\begin{abstract}
This article measures the ideology of Brazilian political parties, recurrently cited as inconsistent. The method applied is the content analysis of party programs, using an alternative scale, proposed to capture Brazilian specificities, usually neglected in the international comparative literature. The party positions are calculated for the main seven Brazilian parties in the left-right dimension and in the conservative-liberal dimension, which are then crossed in a two-dimensional plane. The results are compared to other classifications found in the literature about Brazil and indicate the relevance of mobilizing the ideological position of parties as independent variable to the understanding of several aspects of the Brazilian party system.
\end{abstract}

\section{Keywords}

Political Parties; Ideology; Content Analysis; Party Manifestos. 


\section{Introdução ${ }^{1}$}

Os partidos políticos são frequentemente mobilizados como variáveis independentes em modelos teóricos os mais diversos: políticas públicas, ciclos de gastos públicos, desempenho dos governos, resultados macroeconômicos, coligações, comportamento do eleitor, atuação parlamentar, governabilidade. Entretanto, um dos principais aspectos do impacto dos partidos sobre outras variáveis está em franca decadência: a ideologia. Como em todo o mundo, as distâncias entre as posições dos partidos na dimensão esquerda-direita vêm se reduzindo e muitas análises têm reportado efeito não significativo desta variável. Além disso, os partidos políticos brasileiros são invariavelmente acusados de desviarem-se das funções que supostamente deveriam cumprir, tais como a representação e canalização das demandas provenientes da sociedade.

Contudo, existem indicadores de que a democracia brasileira, cuja consolidação parece não haver dúvidas, funciona em bases partidárias: são os partidos que selecionam as elites políticas e formam o legislativo e o governo. A transformação no papel que os partidos exercem nas democracias já foi descrita e teorizada por vários autores, mas no Brasil parece não ter sido bem acolhida. Exemplo disso é a reiterada denúncia da ausência de vínculos societários, que seria responsável pela alegada instabilidade do sistema partidário brasileiro. Abordagens teóricas como a dos "cartel parties", por exemplo, que se afastam das concepções clássicas, têm aparecido nas análises do arranjo institucional brasileiro, especialmente no que se refere às relações entre executivo e legislativo. Mas nos estudos específicos da área de partidos políticos, raramente se encontram referências que superem a inovação que o conceito de partido "catch all" representou nos anos sessenta do século XX.

A discussão que se propõe aqui parte do pressuposto de que conhecer as preferências políticas dos partidos brasileiros é importante para compreender o funcionamento do sistema partidário e todas aquelas demais variáveis dependentes citadas acima. Trata-se de identificar o conteúdo das preferências políticas dos partidos e de acessá-las analiticamente em um contexto de esmorecimento das diferenças ideológicas. Para isso, é necessário lançar mão de recursos teóricos e metodológicos inovadores ${ }^{2}$, que superem os impasses gerados pela crise de representatividade dos partidos.

\footnotetext{
${ }^{1}$ Este trabalho reúne discussões iniciadas em trabalhos anteriores apresentados em congressos no Brasil, Argentina e Estados Unidos, resultantes de pesquisa desenvolvida com o auxílio do CNPq. Trata-se de um balanço geral do que produzimos no programa de pesquisa de três anos que estamos concluindo agora, com este artigo. Agradecemos a todos os colegas que nos ajudaram com suas sugestões e críticas em todas as oportunidades que tivemos de discutir estes trabalhos.

${ }^{2}$ Trata-se da abordagem da análise de conteúdo dos programas partidários, desenvolvida pelo Manifestos Research Group, mas ainda pouco explorada no Brasil. Esta é a abordagem aplicada neste estudo, e será descrita com detalhes adiante.
} 
Ao mesmo tempo em que parece não haver controvérsia quanto à ordenação dos partidos brasileiros no eixo esquerda-direita ${ }^{3}$, a sua identidade política é reiteradamente posta em dúvida, seja pela imprensa, seja por analistas acadêmicos, ou ainda nos resultados das pesquisas de opinião pública. Parece haver um descompasso entre a validade do ainda persistente uso da ideologia partidária como variável explicativa (em análises de resultados eleitorais, coligações, políticas públicas) e o diagnóstico corrente de inconsistência ideológica dos partidos brasileiros.

É possível que este descompasso se deva a um problema de identificação das preferências políticas dos partidos. Em trabalhos anteriores, discutimos algumas estratégias metodológicas para aferir posicionamentos ideológicos (TAROUCO e MADEIRA, 2013). A análise de conteúdo dos documentos programáticos dos partidos é uma das alternativas possíveis para acessar as suas preferências políticas ${ }^{4}$. A extensão de texto dedicada a cada tema pode ser tomada como indicativa da ênfase atribuída pelo partido a cada questão. Neste trabalho, valemo-nos novamente desta abordagem para mensurar o peso de determinadas categorias de assuntos nos manifestos partidários.

Esta abordagem está baseada no trabalho do MRG - Manifestos Research Group (BUDGE et. al., 2001; VOLKENS, 2001), que elaborou uma lista de categorias para a classificação das frações de texto e também propôs uma escala de esquerda-direita a partir da seleção de algumas dentre aquelas categorias ${ }^{5}$. As categorias indicativas de posicionamento à direita, segundo a escala proposta pelo MRG, são: Forças Armadas (positivo), Liberdades e Direitos Humanos, Constitucionalismo (positivo), Autoridade Política, Livre Iniciativa, Incentivos, Protecionismo (negativo), Ortodoxia Econômica, Limitação do Welfare State, Nacionalismo (positivo), Moralidade Tradicional (positivo), Lei e Ordem, Harmonia Social. As categorias indicativas de esquerda, na mesma referida escala, são: Anti-Imperialismo, Forças Armadas (negativo), Paz, Internacionalismo (positivo), Democracia, Regulação do Mercado, Planejamento Econômico, Protecionismo (positivo), Economia Controlada, Nacionalização, Expansão do Welfare State, Expansão da Educação, Classes Trabalhadoras (positivo). (KLINGEMANN et. al., 2006) ${ }^{6}$.

\footnotetext{
${ }^{3}$ As análises que mobilizam ideologia partidária quase invariavelmente classificam PT e PDT na esquerda, PMDB e PSDB no centro e PDS/PPR/PPB/PP, PTB e PFL/DEM na direita.

${ }^{4}$ As demais incluem avaliação de especialistas (acadêmicos ou da imprensa), percepção da opinião pública, comportamento parlamentar e auto-declaração dos políticos.

${ }^{5}$ A lista completa das categorias está disponível no apêndice.

${ }^{6} \mathrm{O}$ esquema de categorias foi elaborado inicialmente para uma análise de manifestos em 19 democracias e publicado em Budge, Robertson e Hearl (1987). Uma revisão das categorias originais foi publicada em Laver and Budge (1992). Pesquisas empregando o esquema de ccategorias foram publicadas em Klingemann, Hofferbert e Budge (1994), em Budge et. al. (2001) e em Klingemann et. al. (2006).
} 
A aplicação direta da referida escala aos partidos brasileiros produziu resultados extremamente distorcidos em comparação com as classificações usuais (TAROUCO e MADEIRA, 2013) e nos levou a questionar a validade daquela escala para a realidade brasileira.

As discrepâncias entre as noções correntes e os resultados encontrados podem estar relacionadas ao fato de que a distinção entre esquerda e direita estaria "contaminada" por categorias relativas à dimensão conservadorismo-liberalismo. Por exemplo, os posicionamentos referentes à tensão entre autoridade política e liberdades e direitos humanos são fundamentais para a identificação política dos partidos brasileiros na transição do regime militar: partidos com passado de apoio à ditadura são por este motivo classificados como de direita e partidos herdeiros da oposição classificados como de esquerda (TAROUCO e MADEIRA, 2010).

Este artigo pretende contribuir para o debate sobre o sistema partidário brasileiro através da análise das posições e preferências dos principais partidos. Na próxima seção, apresentamos brevemente a escala esquerda-direita elaborada a partir das categorias do Manifestos Research Group. Em seguida, propomos uma escala de conservadorismo e o seu cruzamento com a primeira escala, em um plano bidimensional. Na seção seguinte, comparamos os posicionamentos dos partidos, mensurados através da análise de conteúdo dos seus programas, com outras classificações correntes na literatura sobre os partidos brasileiros, produzidas com outros métodos. Por fim, concluímos com algumas considerações sobre a validade da variável ideologia e a sua importância para o estudo do sistema partidário brasileiro.

\section{A dimensão esquerda-direita}

A relevância do período autoritário já foi demonstrada em outros trabalhos (MADEIRA, 2006) no que se refere à configuração do multipartidarismo atual. Também na identificação dos partidos na dimensão esquerda-direita é decisiva a herança dos posicionamentos dos partidos durante o regime militar (MADEIRA e TAROUCO, 2010). Por este motivo, uma escala ideológica que se pretenda aplicável ao Brasil não pode deixar de considerar este aspecto histórico específico.

A isto os governos da década de 90 adicionaram questões relativas à liberalização econômica: o posicionamento diante das políticas de privatização e desregulamentação, por exemplo, passaram a ser levados em conta na identificação dos partidos em termos de esquerda e direita (POWER, 2008). Por este motivo, o critério econômico (posicionamento em relação ao peso desejável da intervenção estatal na economia), dominante na ciência política para a identificação ideológica (DOWNS, 1999), pode e deve ser mantido em uma escala específica para os partidos brasileiros. Este argumento está de acordo com Power (2008) que afirma: 
The persistence of authoritarian-era cleavages colored Brazilian politics for at least the first decade after the transition to democracy, but the Plano Real and the election of Cardoso in 1994 inaugurated a new phase of economic and political management. The Plano Real ended hyperinflation, the alliance between the PSDB and PFL united forces that were on opposite sides of the coup of 1964, a broad reform agenda reshaped the overall development model in significant ways, and Cardoso's effective manipulation of "coalitional presidentialism" rewrote the playbook for the management of interparty alliances and power sharing. These changes had the effect of "rebooting" the democratic regimes in the mid-1990's sharply diminishing the relevance of the authoritarian-era cleavages that had shaped, for example, the writing of Brazil's new constitution in the late 1980s. This process has been reinforced by intergenerational population replacement within the political class: simply put, older politicians have died and younger ones have taken their place. The new recruits do not carry the baggage of 1964. (POWER, 2008, p. 84).

A pertinência do critério downsiano, entretanto, longe de resolver as dificuldades de adequação dos conceitos de direita e esquerda à realidade brasileira, acrescenta ainda mais um problema: a distinção entre esquerda e direita pelo grau de intervenção estatal na economia não distingue a intervenção redistributiva da intervenção "pró-capital". No Brasil foram exatamente os governos da ditadura militar que adotaram barreiras comerciais à importação com o objetivo de alavancar o desenvolvimento da indústria nacional, assim como em vários momentos da história tem sido a direita a demandar a atuação do Estado na economia, em descompasso com o laissez-faire e o estado mínimo que caracterizam o liberalismo econômico na Europa. Entendemos que este aparente paradoxo poderá ser adequadamente tratado se distinguirmos o liberalismo econômico das suas outras formas, pertencentes à dimensão do conservadorismo.

Levando tudo isso em consideração, reformulamos a escala elaborada pelo MRG e assim, chegamos às seguintes categorias como indicativas, no Brasil, de posicionamento à direita: menções positivas às forças armadas, livre iniciativa, incentivos, ortodoxia econômica, limitação do Welfare State e referências favoráveis à classe média e grupos profissionais (para contrastar com as referências à classe operária). As categorias selecionadas como indicativas de posicionamento à esquerda são a seguintes: regulação do mercado, planejamento econômico, economia controlada, análise marxista, expansão do Welfare State e referências positivas à classe trabalhadora ${ }^{7}$.

\footnotetext{
${ }^{7}$ As categorias regulação do mercado, planejamento econômico e economia controlada já estavam presentes na escala original do MRG como indicativas da posição à esquerda e foram mantidas porque entendemos que, apesar de serem observadas também entre as políticas públicas de governos de centro e de direita, estas são bandeiras emblemáticas dos partidos socialistas, no sentido da intervenção do estado contra os efeitos perversos do livre funcionamento dos mercados capitalistas. Além disso, a distinção mínima de esquerda e direita consolidada na Ciência Política
} 
Esta escala foi feita seguindo o modelo da escala esquerda-direita de Klingemann et. al. (2006), que subtrai a proporção de texto dos documentos dedicada a categorias de esquerda do total da proporção de texto dedicada a categorias de direita. Valores negativos representam posições de esquerda e valores positivos representam posições de direita. Um caso hipotético em que um manifesto inteiro fosse dedicado a categorias indicativas de esquerda teria o valor de -100; por outro lado, um documento cujo texto contivesse apenas categorias indicativas de direita teria o valor de 100 na escala.

A análise de conteúdo dos manifestos dos principais partidos brasileiros a partir das categorias do MRG permite classificá-los conforme a tabela 1 a seguir, que compara os resultados obtidos a partir da escala original do MRG com aqueles produzidos pela aplicação da nossa escala adaptada:

Tabela 1 - Posição dos partidos segundo as duas escalas

\begin{tabular}{c|c|c}
\hline Manifesto & Posição na escala MRG & Posição na escala adaptada \\
\hline PDS 1979 & $-15,1$ & $-7,2$ \\
\hline PPB 1995 & $-14,1$ & $-5,2$ \\
\hline PP 2003 & $-14,3$ & $-5,2$ \\
\hline PDT 1979 & $-37,3$ & $-23,4$ \\
\hline PDT 1994 & $-10,3$ & $-12,0$ \\
\hline PT 1980 & $-34,4$ & $-13,8$ \\
\hline PT 1990 & $-22,0$ & $-12,4$ \\
\hline PTB 1979 & $-36,8$ & $-22,9$ \\
\hline PTB 2001 & $-27,7$ & $-20,2$ \\
\hline PMDB 1981 & $-25,0$ & $-16,3$ \\
\hline PMDB 1994 & $-8,5$ & $-1,2$ \\
\hline PFL 1995 & 6,5 & 9,8 \\
\hline PFL 2005 & $-3,6$ & 6,0 \\
\hline PFL pré88 & $-5,4$ & $-4,9$ \\
\hline PSDB 1988 & $-13,6$ & $-3,3$ \\
\hline PSDB 2001 & $-0,4$ & 6,5 \\
\hline FOnt Elaboraç & & \\
\hline
\end{tabular}

Fonte: Elaboração própria.

O gráfico 1 a seguir mostra que a adaptação da escala preservou a ordenação dos partidos em relação uns aos outros, reduzindo apenas a amplitude da variação e assim a discrepância com as classificações correntes. $\mathrm{O}$ índice de correlação de Pearson entre as duas escalas é de 0,924.

(Downs, 1999) define a dimensão ideológica como um gradiente que vai do controle governamental pleno (esquerda) até o mercado completamente livre (direita). 
Gráfico 1 - Posição ideológica dos partidos segundo as duas escalas

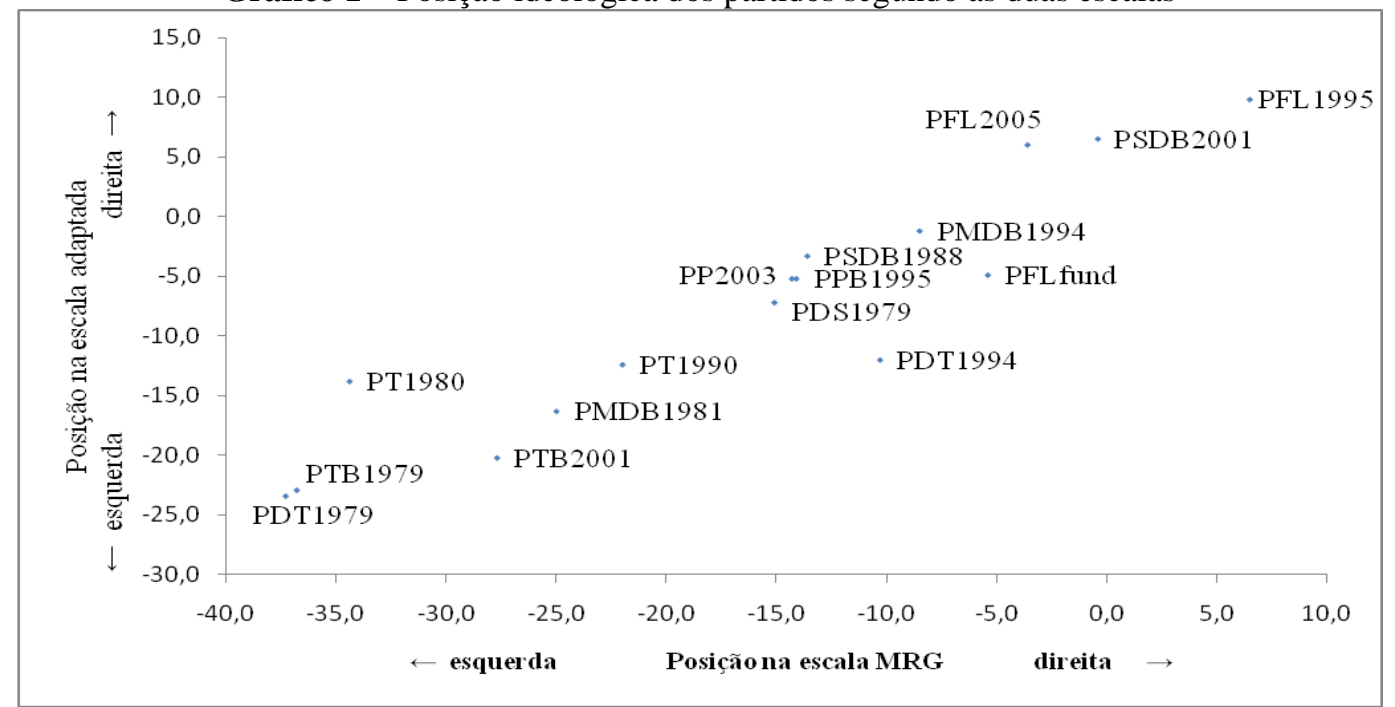

Fonte: Elaboração própria.

Os dados acima mostram um quadro que guarda poucas relações com a classificação usual dos partidos brasileiros, mas indica alguma consistência no que se refere aos principais partidos emblemáticos das posições de esquerda e direita, o PT e o PFL, respectivamente. É possível pensar algumas explicações ad hoc para os resultados referentes aos textos do PDT e PTB em 1979 (a ligação de origem com a carta de Lisboa, resultante de um encontro internacional de partidos socialistas), mas parece mais interessante observar o movimento no tempo entre as versões programáticas dos partidos. Todos se deslocaram da esquerda para a direita. A única exceção é a revisão de 2005 do manifesto do PFL. Vejamos na próxima seção como a escala de conservadorismo pode ajudar a compreender melhor este quadro.

\section{A dimensão do conservadorismo}

Tal qual a dimensão esquerda-direita, a dimensão do conservadorismo não está isenta de controvérsia. Para isso contribuem, por exemplo, a confusão com as dimensões étnicas, nacionais e religiosas, a emergência do neoconservadorismo e a variedade de definições do polo oposto ao conservador, que ora aparece contrastado com posições liberais, ora com progressistas ${ }^{8}$.

Apesar de muito frequentemente os portadores da ideologia de direita serem também conservadores, inclusive no Brasil, argumentamos que o eixo

\footnotetext{
${ }^{8}$ Como definiremos a seguir, a escolha entre estas duas categorias implica algum risco de ambiguidade e portanto de imprecisão: por exemplo, o liberalismo, se definido no sentido da contraposição ao intervencionismo, não exclui preferências conservadoras em termos de moralidade, comportamentos e tradições. Neste artigo nos referimos ao liberalismo no sentido não econômico, como será discutido adiante.
} 
esquerda-direita não se confunde com o eixo liberal-conservador, mas, antes, é cortado por ele, definindo um espaço político bidimensional. A seleção de categorias para compor uma escala de conservadorismo é a proposta desta seção.

Há um extenso debate na teoria política a respeito das definições de conservadorismo e liberalismo. Este debate coloca vários problemas conceituais que não poderemos enfrentar nos limites deste trabalho, mas que mencionamos a seguir apenas para situar nossas escolhas.

O primeiro desafio é estabelecer a qual ideologia o conservadorismo se opõe. Na literatura de filosofia política e de história das ideias a dualidade é ora composta com o pensamento liberal, ora com o progressista. No caso de optarmos pelo liberalismo, o segundo desafio é especificar a qual liberalismo nos referimos: se ao liberalismo clássico ou à sua versão contemporânea; se ao liberalismo econômico ou político. Além disso, há ainda a alegada alternância entre as posições conservadora e liberal, conforme a variação do status quo. Longe de pretender resolver tais questões, recorremos a algumas noções geralmente adotadas que, apesar de muito básicas, parecem gozar de algum consenso, ao menos na bibliografia de ciência política.

Assim, consideraremos, para fins desta análise, que o conservadorismo pode ser entendido como um conjunto de posicionamentos de defesa do controle social pelo Estado contra a falibilidade do indivíduo; de defesa da tradição contra mudanças sociais radicais; de uma defesa organicista do caráter nacional. Em consequência desta definição, consideraremos que a posição oposta inclui elementos emblemáticos do liberalismo (não econômico), tais como a defesa de direitos e liberdades individuais contra a intervenção do Estado; a defesa dos direitos de minorias contra a discriminação e a segregação social; a defesa dos cidadãos contra arbitrariedades dos governos.

Entre as categorias do MRG (KLINGEMANN e VOLKENS et. al. 2006), selecionamos as seguintes para refletirem tais elementos:

Quadro 1 - Composição da escala de conservadorismo

\begin{tabular}{|c|c|}
\hline \multicolumn{2}{|c|}{$\begin{array}{c}\text { Categorias indicativas de } \\
\text { posicionamento conservador }\end{array}$} \\
\hline 305 & Autoridade Política \\
\hline 601 & Modo nacional de vida \\
\hline 603 & Moralidade tradicional: positivo \\
\hline 606 & Harmonia social \\
\hline
\end{tabular}

\begin{tabular}{|c|c|}
\hline \multicolumn{2}{|c|}{$\begin{array}{c}\text { Categorias indicativas de } \\
\text { posicionamento liberal }\end{array}$} \\
\hline 201 & Liberdades e Direitos Humanos \\
\hline 303 & $\begin{array}{c}\text { Eficiência Govern. e } \\
\text { Administrativa }\end{array}$ \\
\hline 604 & Moralidade tradicional: negativo \\
\hline 705 & Minorias desprivilegiadas \\
\hline
\end{tabular}

Fonte: Elaboração própria.

Esta escala foi feita seguindo o modelo da escala esquerda-direita descrita acima. Assim, aqui, subtraímos a proporção de texto dos documentos dedicada a categorias de liberalismo do total da proporção de texto dedicada a categorias de conservadorismo. Valores negativos representam posições liberais (no sentido do liberalismo não econômico, conforme assinalado acima) e valores positivos 
representam posições conservadoras. Um caso hipotético em que um manifesto inteiro fosse dedicado a categorias indicativas de liberalismo teria o valor de -100 ; por outro lado, um documento cujo texto contivesse apenas categorias indicativas de conservadorismo teria o valor de 100 na escala.

A análise de conteúdo dos manifestos dos principais partidos brasileiros a partir das categorias do MRG permite classificá-los conforme as tabelas 2, 3 e 4 abaixo:

Tabela 2 - Porcentagem de texto dedicado a categorias de Conservadorismo

\begin{tabular}{c|c|c|c|c|c}
\hline Manifesto & $\begin{array}{c}\text { Autoridade } \\
\text { Política }\end{array}$ & $\begin{array}{c}\text { Modo nacional } \\
\text { de vida }\end{array}$ & $\begin{array}{c}\text { Moralidade } \\
\text { tradicional: } \\
\text { positivo }\end{array}$ & $\begin{array}{c}\text { Harmonia } \\
\text { social }\end{array}$ & Total \\
\hline PDS 1979 & 0,0 & 1,5 & 0,2 & 0,2 & 2,0 \\
\hline PPB 1995 & 0,0 & 1,9 & 0,6 & 0,0 & 2,5 \\
\hline PP 2003 & 0,0 & 1,9 & 0,6 & 0,0 & 2,5 \\
\hline PDT 1979 & 0,0 & 4,1 & 0,0 & 0,0 & 4,1 \\
\hline PDT 1994 & 0,0 & 1,4 & 0,0 & 0,0 & 1,4 \\
\hline PT 1980 & 0,0 & 0,0 & 0,0 & 0,0 & 0,0 \\
\hline PT 1990 & 0,0 & 0,1 & 0,0 & 0,0 & 0,1 \\
\hline PTB 1979 & 0,0 & 3,7 & 0,0 & 0,0 & 3,7 \\
\hline PTB 2001 & 0,0 & 1,5 & 0,0 & 0,9 & 2,4 \\
\hline PMDB & 0,0 & 2,2 & 0,0 & 0,2 & 2,4 \\
\hline PMDB & 0,0 & 3,0 & 0,0 & 0,0 & 3,0 \\
\hline PFL 1995 & 0,0 & 0,6 & 0,4 & 0,0 & 1,0 \\
\hline PFL 2005 & 0,7 & 0,0 & 0,0 & 1,2 & 1,9 \\
\hline PFL fund & 0,4 & 1,1 & 0,0 & 1,4 & 2,8 \\
\hline PSDB 1988 & 1,1 & 0,0 & 0,0 & 0,0 & 1,1 \\
\hline PSDB 2001 & 0,0 & 0,0 & 0,0 & 0,3 & 0,3 \\
\hline Font Elaboracis & & & & \\
\hline
\end{tabular}

Fonte: Elaboração própria. 
Tabela 3 - Porcentagem de texto dedicado a categorias de Liberalismo

\begin{tabular}{c|c|c|c|c|c}
\hline Manifesto & $\begin{array}{c}\text { Liberdades e } \\
\text { Direitos } \\
\text { Humanos }\end{array}$ & $\begin{array}{c}\text { Eficiência } \\
\text { Governamental e } \\
\text { Administrativa }\end{array}$ & $\begin{array}{c}\text { Moralidade } \\
\text { tradicional: } \\
\text { negativo }\end{array}$ & $\begin{array}{c}\text { Minorias } \\
\text { desprivile- } \\
\text { giadas }\end{array}$ & Total \\
\hline PDS 1979 & 3,4 & 0,0 & 0,0 & 0,61 & 4,0 \\
\hline PPB 1995 & 2,5 & 1,1 & 0,0 & 0,00 & 3,6 \\
\hline PP 2003 & 2,5 & 1,2 & 0,0 & 0,00 & 3,7 \\
\hline PDT 1979 & 2,6 & 0,0 & 0,0 & 0,00 & 2,6 \\
\hline PDT 1994 & 2,1 & 1,1 & 0,0 & 0,13 & 3,4 \\
\hline PT 1980 & 1,1 & 0,0 & 0,0 & 0,00 & 1,1 \\
\hline PT 1990 & 1,5 & 0,0 & 0,0 & 0,00 & 1,5 \\
\hline PTB 1979 & 2,6 & 0,0 & 0,0 & 0,00 & 2,6 \\
\hline PTB 2001 & 0,9 & 0,0 & 0,0 & 0,00 & 0,9 \\
\hline PMDB 1981 & 2,3 & 0,0 & 0,0 & 0,06 & 2,4 \\
\hline PMDB 1994 & 0,4 & 1,7 & 0,2 & 0,00 & 2,3 \\
\hline PFL 1995 & 1,3 & 0,8 & 0,0 & 0,00 & 2,1 \\
\hline PFL 2005 & 1,7 & 3,1 & 0,0 & 0,00 & 4,8 \\
\hline PFL fund & 6,3 & 2,7 & 0,0 & 0,12 & 9,1 \\
\hline PSDB 1988 & 0,5 & 4,8 & 0,0 & 0,00 & 5,2 \\
\hline PSDB 2001 & 0,0 & 0,3 & 0,3 & 1,09 & 1,7 \\
\hline FOS & & & &
\end{tabular}

Fonte: Elaboração própria.

Tabela 4 - Cálculo da posição na escala de conservadorismo

\begin{tabular}{c|c|c|c}
\hline Manifesto & Conservadorismo & Liberalismo & Cons. - Lib. \\
\hline PDS 1979 & 2,0 & 4,0 & $-2,1$ \\
\hline PPB 1995 & 2,5 & 3,6 & $-1,1$ \\
\hline PP 2003 & 2,5 & 3,7 & $-1,2$ \\
\hline PDT 1979 & 4,1 & 2,6 & 1,5 \\
\hline PDT 1994 & 1,4 & 3,4 & $-2,0$ \\
\hline PT 1980 & 0,0 & 1,1 & $-1,1$ \\
\hline PT 1990 & 0,1 & 1,5 & $-1,4$ \\
\hline PTB 1979 & 3,7 & 2,6 & 1,2 \\
\hline PTB 2001 & 2,4 & 0,9 & 1,5 \\
\hline PMDB 1981 & 2,4 & 2,4 & 0,1 \\
\hline PMDB 1994 & 3,0 & 2,3 & 0,7 \\
\hline PFL 1995 & 1,0 & 2,1 & $-1,1$ \\
\hline PFL 2005 & 1,9 & 4,8 & $-2,9$ \\
\hline PFL fund & 2,8 & 9,1 & $-6,3$ \\
\hline PSDB 1988 & 1,1 & 5,2 & $-4,1$ \\
\hline PSDB 2001 & 0,3 & 1,7 & $-1,3$ \\
\hline
\end{tabular}

Fonte: Elaboração própria. 
Gráfico 2 - Ordenação segundo valores na escala de conservadorismo

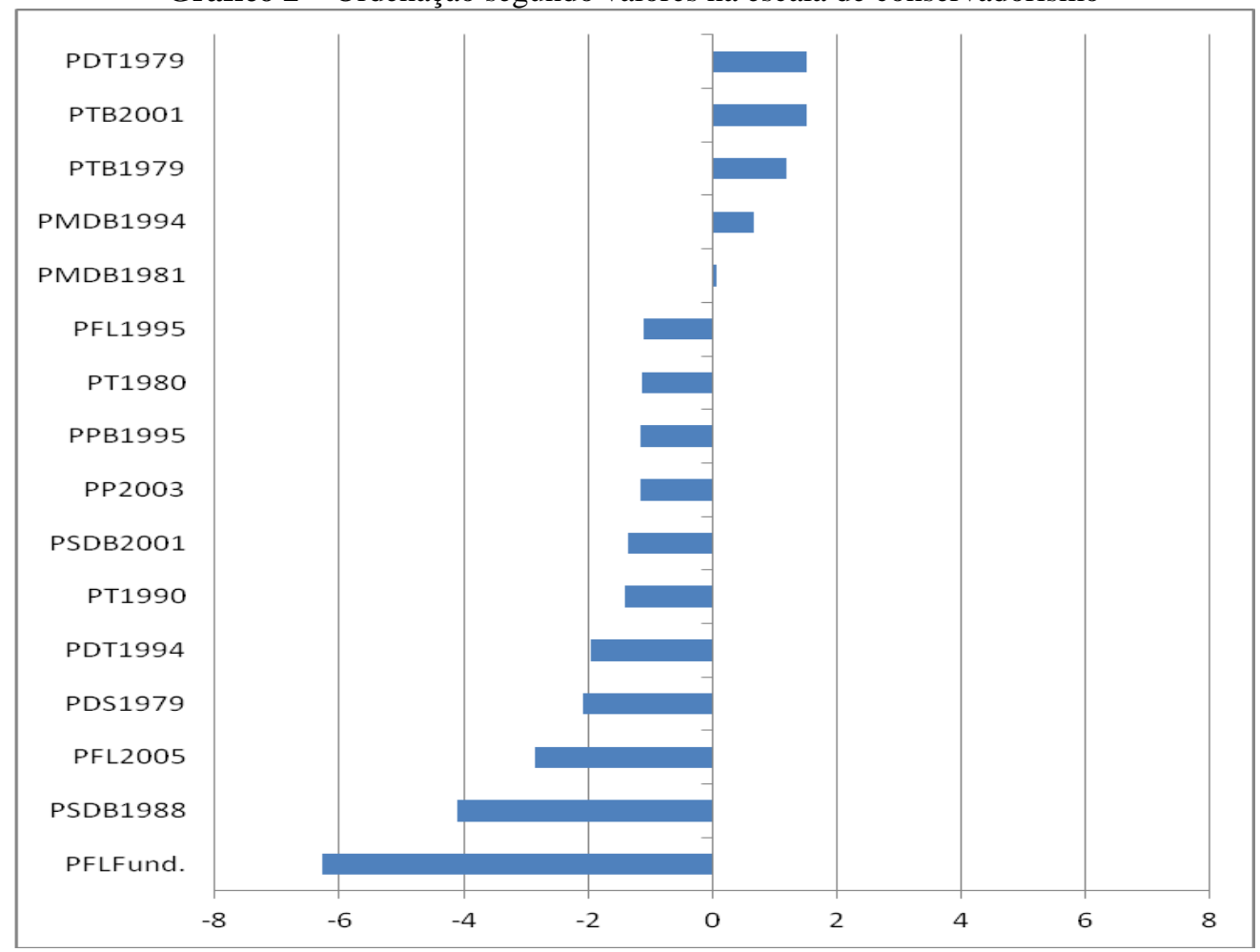

Fonte: Elaboração própria.

É interessante observar que em quase todos os partidos, com o passar do tempo, os programas se moveram de posições liberais para posições mais conservadoras (ou menos liberais). As exceções são o PDT e, novamente, a segunda revisão do manifesto do PFL, em 2005. Uma possibilidade de explicação deste movimento é a mudança de uma conjuntura inicial de transição do regime, em que todos os partidos se colocavam como engajados em transformações necessárias, para uma situação posterior de consolidação, em que, avançado o processo das mudanças inicialmente defendidas, aos partidos restam mais conquistas a defender (e a reivindicar como tributárias de sua colaboração) do que transformações a exigir.

Vejamos, na próxima seção, como o cruzamento da dimensão esquerdadireita com a dimensão do conservadorismo pode ajudar a compreender este quadro.

\section{O plano bidimensional}

Conforme nossa proposta inicial, o gráfico a seguir mostra o posicionamento dos programas partidários, segundo seus valores nas escalas de esquerda-direita e de conservadorismo. 
Gráfico 3 - Posição dos documentos partidários segundo as duas escalas

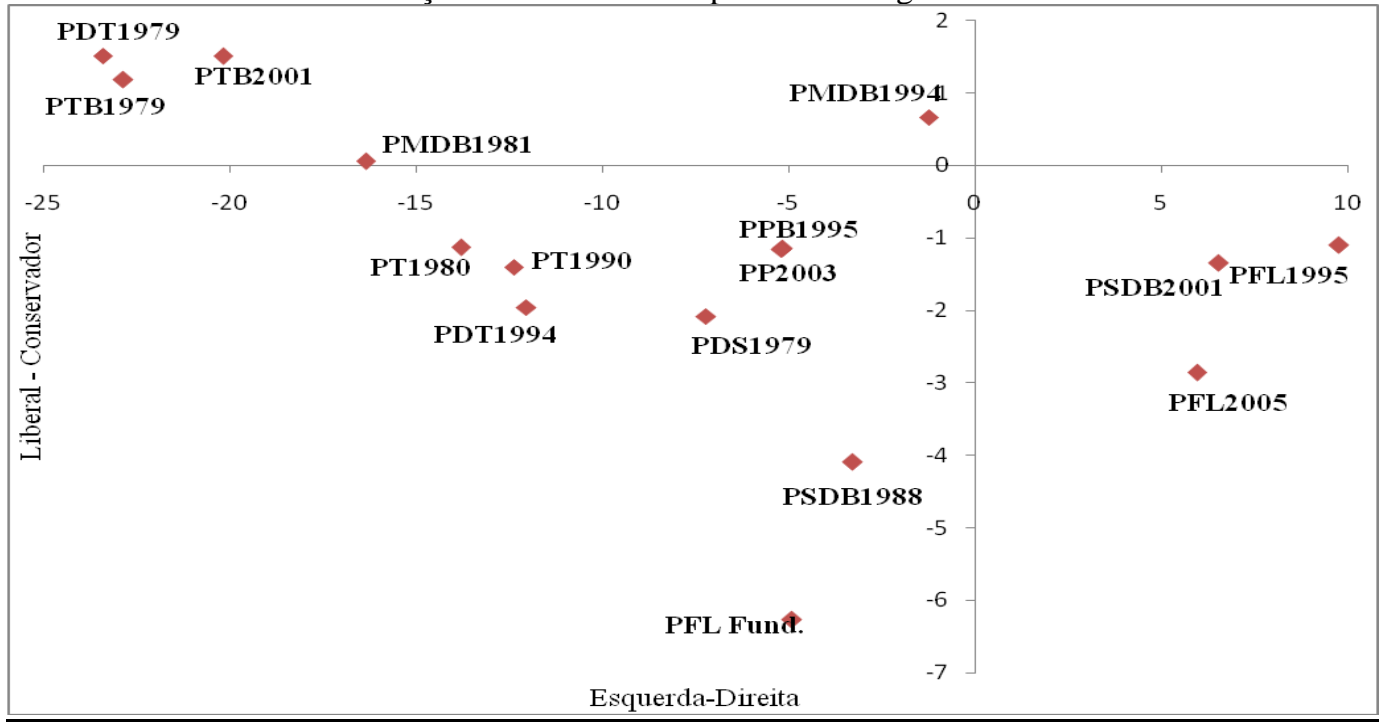

Fonte: Elaboração própria.

Observa-se que metade dos manifestos ficou situada no quadrante inferior esquerdo (liberal de esquerda). A outra metade se distribui entre o quadrante inferior direito (liberal de direita) e superior esquerdo (conservador de esquerda). Nenhum dos textos analisados pode ser posicionado como conservador de direita.

Esta distribuição bidimensional ajuda a perceber que, de acordo com o conteúdo dos documentos programáticos, os partidos parecem ter alguma identidade no espaço de competição política. O PFL e o PSDB de 2001, partidos aliados na condução de políticas liberalizantes de mercado na década de 90 ocupam posições próximas. Os manifestos do PDT e PTB ocupam posições próximas, exceto pelo manifesto de 1994 do PDT. O PT e o PDS/PPB/PP, geralmente indicados como exemplares de campos opostos, mantiveram-se no mesmo campo mesmo depois das mudanças efetuadas nos programas. Por fim, o PMDB esteve sempre perto do centro: em 1981, do centro da escala de conservadorismo, e em 1994, do centro da escala de esquerda-direita.

Cabe aqui um breve comentário sobre as combinações resultantes do cruzamento: se as duas dimensões analisadas não fossem distintas, como argumentamos que sejam, teríamos observado menos casos (ou nenhum caso) de conservadores de esquerda ou de liberais de direita. A ocorrência destas observações confirma que uma posição política de esquerda é compatível com uma posição conservadora - a rigor nada impede que a defesa de interesses da classe trabalhadora conviva com padrões culturais e de comportamento ditados pela tradição, dado que este conservadorismo em princípio pode não constituir obstáculo direto à luta por políticas redistributivas, por exemplo.

Finalmente, é possível que as classificações nos eixos esquerda-direita e liberal-conservador, elaboradas até agora, tenham que ser ponderadas pelo fato de 
que alguns partidos parecem conferir mais importância a questões que não se enquadram nestas dimensões. Há certamente mais dimensões ao longo das quais os partidos se posicionam, além destas duas que discutimos neste trabalho, como por exemplo, uma possível dimensão materialista - pós-materialista (INGLEHART, 1990). Assim, o espaço de competição política seria multidimensional, o que poderia significar até que o esforço em identificar e mensurar cada uma das suas várias dimensões ou seria infrutífero ou produziria resultados cuja complexidade, em vez de ajudar, comprometeria a análise.

\section{Comparando os resultados com outras classificações correntes dos partidos brasileiros}

A literatura apresenta diferentes métodos de aferição da posição de um partido no eixo esquerda-direita. Cada um tem suas limitações, porque posições políticas são conceitos abstratos que não podem ser observados diretamente e qualquer método utilizado para estimá-las pode apenas apreender algumas de suas manifestações empíricas9. Discutiremos brevemente as classificações feitas a partir da análise de manifestos, de surveys com eleitores, de surveys com especialistas e de análises do comportamento parlamentar.

O problema de recorrer aos documentos programáticos seria, segundo Miguel (2010), o pressuposto ingênuo de que a competição política realmente corresponda a uma disputa entre plataformas diferentes. Esta é a abordagem do presente artigo.

Já o problema de tomar a classificação dos eleitores como indicador da real posição do partido apontado por Budge (2000; BUDGE, VOLKENS et. al. 2001) é de que as percepções eleitorais a respeito dos partidos políticos deveriam ser tomadas como variável dependente que pode ou não coincidir com a tentativa do partido de definir sua própria posição. Esta abordagem é aplicada por Singer (2002).

O problema da classificação direta, em que cada entrevistado deve definir sua posição na escala esquerda-direita, é que cada entrevistado pode ter um entendimento diferente do que seja esquerda e direita e isto pode comprometer a validade da mensuração.

As análises indiretas, que mobilizam outras categorias para deduzir o posicionamento na escala, têm pelo menos dois tipos de problemas. $\mathrm{O}$ primeiro emerge quando se adota comportamento (por exemplo, as votações dos parlamentares) como indicador de posicionamento ideológico, como fazem Fernandes (1995) e Leoni (2002). Zucco Jr. (2009) aponta para o conteúdo estratégico que afeta os comportamentos no legislativo e demonstra que em configurações presidenciais multipartidárias, a atuação parlamentar é resultante não apenas da ideologia, mas também do cálculo eleitoral e das relações entre o

\footnotetext{
${ }^{9}$ Uma discussão exaustiva de todas estas opções metodológicas e suas conseqüências substantivas pode ser encontrada em Benoit e Laver (2006).
} 
governo e os partidos no legislativo. Assim, a variável comportamento parlamentar, por seus aspectos estratégicos, não seria uma boa medida para o conceito de posicionamento ideológico. O segundo problema é como determinar quais categorias (comportamentos, atitudes ou opiniões) são indicativas de posicionamento de esquerda e quais de direita. Power e Zucco (2011) enfrentam este problema para converter em posicionamento ideológico as respostas dos parlamentares a uma série de perguntas sobre economia e política.

O problema de adotar o julgamento de especialistas (acadêmicos ou da imprensa), por sua vez, está na validade das medidas produzidas desta forma. Segundo Budge (2000), o problema estaria na indefinição de qual aspecto dos partidos é avaliado pelos especialistas. Por mais que os critérios sejam claramente definidos no questionário, não seria possível determinar o quê é levado em conta pelos especialistas no momento da avaliação. Se os julgamentos se basearem, em qualquer medida, em comportamentos dos partidos ou seus membros, estes mesmos julgamentos já não podem mais, sob o risco de produzir circularidade, ser usados para explicar atuação dos partidos em governos, por exemplo, que também constitui comportamento ${ }^{10}$.

Os partidos brasileiros foram submetidos a esta abordagem em pelo menos duas pesquisas: Wiesehomeier e Benoit (2007) aplicaram questionários pela internet, entre o final de 2006 e início de 2007, pedindo que analistas brasileiros classificassem os principais partidos em uma escala de 20 pontos onde 1 correspondia a esquerda e 20 a direita. Depois, em 2010, durante o encontro da Associação Brasileira de Ciência Política (ABCP), os participantes das áreas temáticas de Eleições e Representação Política e de Instituições foram convidados a responder um questionário onde os partidos políticos brasileiros deveriam ser classificados em uma escala de sete pontos, em que 1 representava extrema esquerda e 7 a extrema direita ${ }^{11}$.

Vejamos os resultados destas diferentes abordagens aplicadas aos partidos brasileiros. A tabela 5 a seguir reúne algumas das classificações presentes na literatura:

\footnotetext{
${ }^{10}$ Mair (2001) compara alguns dos mais conhecidos surveys que já foram feitos com especialistas em vários países e mostra como as classificações resultantes não coincidem, sugerindo problemas de validade e confiabilidade nestas medidas.

${ }^{11}$ Os resultados deste último são discutidos detalhadamente em Tarouco e Madeira (2012a).
} 
Tabela 5 - Classificações dos partidos políticos brasileiros

\begin{tabular}{|c|c|c|c|c|c|c|c|}
\hline Autor & $\begin{array}{c}\text { Coppedge* } \\
\text { (1997) }\end{array}$ & $\begin{array}{l}\text { Power e } \\
\text { Zucco } \\
(\mathbf{2 0 1 1})^{* *}\end{array}$ & $\begin{array}{l}\text { Mainwaring } \\
\text { et. al. } \\
(2000)^{* * *}\end{array}$ & $\begin{array}{c}\text { Wiesehomeier } \\
\text { e Benoit } \\
(2007)^{* * * *}\end{array}$ & $\begin{array}{l}\text { Tarouco e } \\
\text { Madeira } \\
(2012 a) \\
* * * * *\end{array}$ & $\begin{array}{c}\text { Tarouco e } \\
\text { Madeira } \\
(2013) \\
* * * * * *\end{array}$ & $\begin{array}{c}\text { Fernandes } \\
(\mathbf{1 9 9 5 )} \\
* * * * * * *\end{array}$ \\
\hline Método & $\begin{array}{c}\text { Compilaçã } \\
\text { o de } \\
\text { avaliações } \\
\text { de outros } \\
\text { analistas }\end{array}$ & $\begin{array}{l}\text { Entrevistas } \\
\text { com } \\
\text { parlamen- } \\
\text { tares }\end{array}$ & $\begin{array}{c}\text { Votações no } \\
\text { Congr. + } \\
\text { survey c/ } \\
\text { parlamen- } \\
\text { tares }\end{array}$ & $\begin{array}{l}\text { Survey } \\
\text { experts }\end{array}$ & $\begin{array}{l}\text { Survey } \\
\text { experts }\end{array}$ & $\begin{array}{l}\text { Análise de } \\
\text { conteúdo } \\
\text { dos } \\
\text { manifes- } \\
\text { tos }\end{array}$ & $\begin{array}{c}\text { Votações na } \\
\text { Constituinte } \\
\text { segundo } \\
\text { outros } \\
\text { autores }\end{array}$ \\
\hline \multicolumn{8}{|l|}{ Partido } \\
\hline PSOL & não consta & 1,6 & não consta & 2,95 & 1,4 & não consta & não consta \\
\hline $\begin{array}{l}\text { PCB/ } \\
\text { PPS }\end{array}$ & SL & 4,8 & não consta & 10,38 & 4,0 & não consta & $\mathrm{E}$ \\
\hline PCdoB & SL & 2,6 & não consta & 4,96 & 2,3 & não consta & $E$ \\
\hline $\begin{array}{l}\text { PDC/ } \\
\text { PSDC }\end{array}$ & SCR & não consta & $\mathrm{CD}$ & não consta & não consta & não consta & não consta \\
\hline $\begin{array}{c}\text { PDS... } \\
\text { PP }\end{array}$ & SR & 7,6 & $\mathrm{D}$ & 16,78 & 6,0 & $-5,20$ & D \\
\hline PDT & SCL & 4,0 & não consta & 8,38 & 3,3 & $-12,00$ & $\mathrm{E}$ \\
\hline $\begin{array}{l}\text { PFL/ } \\
\text { DEM }\end{array}$ & SR & 7,8 & D & 17,33 & 6,2 & 6,00 & D \\
\hline $\begin{array}{c}\text { PJ/PRN/ } \\
\text { PTC }\end{array}$ & $\mathrm{P}$ & não consta & $\mathrm{D}$ & não consta & não consta & não consta & não consta \\
\hline PL & SR & não consta & $\mathrm{D}$ & não consta & não consta & não consta & $\mathrm{D}$ \\
\hline PR & não consta & 6,9 & não consta & não consta & não consta & não consta & não consta \\
\hline PMDB & $\mathrm{SC}$ & 5,9 & não consta & 11,50 & 4,2 & $-1,20$ & $\mathrm{C}$ \\
\hline PMN & $\mathrm{U}$ & não consta & $\mathrm{CD}$ & não consta & não consta & não consta & $E$ \\
\hline PRONA & SR & não consta & $\mathrm{D}$ & não consta & não consta & não consta & $\mathrm{D}$ \\
\hline PRP & $\mathrm{U}$ & não consta & não consta & não consta & não consta & não consta & $\mathrm{D}$ \\
\hline PSB & SL & 3,7 & não consta & 7,50 & 3,0 & não consta & $\mathrm{E}$ \\
\hline PSC & $\mathrm{XC}$ & não consta & $\mathrm{CD}$ & 15,62 & 5,2 & não consta & $\mathrm{D}$ \\
\hline PSD & SR & não consta & $\mathrm{D}$ & não consta & não consta & não consta & $\mathrm{D}$ \\
\hline PSDB & SCL & 5,8 & não consta & 13,46 & 4,6 & 6,50 & $\mathrm{C}$ \\
\hline PSL & não consta & não consta & $\mathrm{CD}$ & não consta & não consta & não consta & não consta \\
\hline PST & SCR & não consta & $\mathrm{CD}$ & não consta & não consta & não consta & não consta \\
\hline PT & SL & 3,6 & não consta & 6,37 & 2,9 & $-13,80$ & $\mathrm{E}$ \\
\hline PTB & SCR & 6,5 & $\mathrm{CD}$ & 13,60 & 5,0 & $-20,20$ & $\mathrm{D}$ \\
\hline PTdoB & $\mathrm{U}$ & não consta & não consta & não consta & não consta & não consta & não consta \\
\hline PTR/PP & SCR & não consta & $\mathrm{CD}$ & não consta & não consta & não consta & $\mathrm{C}$ \\
\hline PV & $\mathrm{O}$ & 4,5 & não consta & 7,36 & 3,5 & não consta & $E$ \\
\hline
\end{tabular}

* XC = Partidos cristãos de centro; SR = Partidos seculares de direita; SCR = Partidos seculares de centro-direita; $\mathrm{SC}=$ Partidos seculares de centro; $\mathrm{SCL}=$ Partidos seculares de centro-esquerda; $\mathrm{SL}$ $=$ Partidos seculares de esquerda; $\mathrm{P}=$ Partidos personalistas; $\mathrm{O}=$ Outros; $\mathrm{U}=$ Desconhecido. $\mathrm{E}=$ Esquerda; $\mathrm{D}=$ Direita; $\mathrm{C}=$ Centro.

** Média calculada a partir dos dados disponibilizados. Escala de 1 (esquerda) a 10 (direita).

$* * * \mathrm{C}=$ Centro; $\mathrm{D}=$ Direita; $\mathrm{CD}=$ Centro-direita.

$* * * *$ Escala de 1 (esquerda) a 20 (direita)

$* * * * *$ Escala de 1 (esquerda) a 7 (direita).

$* * * * * *$ Escala de -100 (esquerda) a +100 (direita). Utilizadas as medidas relativas aos programas mais recentes.

$* * * * * * * \mathrm{C}=$ Centro; $\mathrm{D}=$ Direita; $\mathrm{E}=$ Esquerda.

Fonte: Adaptado de Tarouco e Madeira (2013).

A análise da tabela acima é dificultada pelo fato de que as diferentes classificações não se aplicam todas aos mesmos partidos, além de serem baseadas em unidades diferentes de medida. Para comparar as classificações, selecionamos 
apenas os partidos que aparecem em todas elas: PDS/.../PP, PDT, PFL/DEM, PMDB, PSDB, PT e PTB e excluímos a classificação de Mainwaring et. al. (2000) porque continha apenas os chamados partidos conservadores. O teste de correlação pode ser verificado na tabela 6 a seguir:

Tabela 6 - Correlação de Spearman entre as 6 medidas de posicionamento ideológico

\begin{tabular}{|c|c|c|c|c|c|c|}
\hline & $\begin{array}{l}\text { Expert } \\
\text { Survey }\end{array}$ & $\begin{array}{c}\text { Conteúdo } \\
\text { Manifestos }\end{array}$ & $\begin{array}{c}\text { Coppedge } \\
(1997)^{12}\end{array}$ & $\begin{array}{c}\text { Fernandes } \\
(\mathbf{1 9 9 5})^{13}\end{array}$ & $\begin{array}{c}\text { Wiesehomeier } \\
\text { e Benoit } \\
(2007)\end{array}$ & $\begin{array}{l}\text { Power } \\
\text { e } \\
\text { Zucco } \\
(\mathbf{2 0 1 1})\end{array}$ \\
\hline $\begin{array}{l}\text { Expert } \\
\text { Survey }\end{array}$ & 1,0 & & & & & \\
\hline $\begin{array}{c}\text { Conteúdo } \\
\text { Manifestos }\end{array}$ & $\begin{array}{c}0,3571 \\
(0,4316)\end{array}$ & $\begin{array}{c}1,0 \\
.\end{array}$ & & & & \\
\hline $\begin{array}{c}\text { Coppedge } \\
\text { (1997) }\end{array}$ & $\begin{array}{c}0,9274 \\
(0,0026)\end{array}$ & $\begin{array}{c}0,1818 \\
(0,6964)\end{array}$ & $\begin{array}{c}1,0 \\
.\end{array}$ & & & \\
\hline $\begin{array}{c}\text { Fernandes } \\
\text { (1995) }\end{array}$ & $\begin{array}{c}0,9449 \\
(0,0013)\end{array}$ & $\begin{array}{c}0,1323 \\
(0,7774)\end{array}$ & $\begin{array}{c}0,9238 \\
(0,0030)\end{array}$ & $\begin{array}{c}1,0 \\
.\end{array}$ & & \\
\hline $\begin{array}{l}\text { Wiesehomeier } \\
\text { e Benoit (2007) }\end{array}$ & 1,0000 & $\begin{array}{c}0,3571 \\
(0,4316) \\
\end{array}$ & $\begin{array}{c}0,9274 \\
(0,0026) \\
\end{array}$ & $\begin{array}{c}0,9449 \\
(0,0013) \\
\end{array}$ & 1,0 & \\
\hline $\begin{array}{c}\text { Power e Zucco } \\
\text { (2011) }\end{array}$ & $\begin{array}{c}0,9643 \\
(0,0005)\end{array}$ & $\begin{array}{c}0,2857 \\
(0,5345)\end{array}$ & $\begin{array}{c}0,9820 \\
(0,0001)\end{array}$ & $\begin{array}{c}0,9449 \\
(0,0013)\end{array}$ & 0,9643 & 1,0 \\
\hline
\end{tabular}

Significância entre parênteses.

Fonte: Elaboração própria.

O teste de correlação mostra que todas as medidas, exceto a da análise de conteúdo dos programas (TAROUCO e MADEIRA, 2013), são fortemente relacionadas, ou seja, de diferentes formas, produzem a mesma ordenação entre os partidos $^{14}$. A análise de conteúdo dos programas, por outro lado, por não estar correlacionada com nenhuma outra medida, parece estar expressando algo diferente das demais. Há várias explicações possíveis para esta discrepância. Uma delas é que os documentos programáticos dos partidos não contenham indicadores suficientes da sua posição ideológica ${ }^{15}$, enquanto as avaliações de especialistas e

\footnotetext{
${ }^{12}$ Escala transformada em numérica ordinal, em que a SR foi codificada como 5, SCR como 4, SC como 3, SCL como 2 e SL como 1.

${ }^{13}$ Escala transformada em numérica ordinal, em que D foi codificada como 3, C como 2 e E como 1.

${ }^{14} \mathrm{O}$ coeficiente de correlação de Spearman varia -1 a +1 . O valor zero indica que duas variáveis não têm qualquer relação entre si. Os valores -1 e +1 indicam a situação em que duas variáveis são perfeitamente correlacionadas. O sinal positivo indica relação direta, ou seja, o aumento nos valores de uma variável acompanha o aumento na outra; o sinal negativo indica relação inversa, ou seja, os valores de uma variável aumentam à medida que os da outra diminuem. A literatura costuma considerar moderados valores de 0,4 a 0,7 e fortes as correlações acima de 0,7 .

${ }^{15}$ Isto estaria de acordo com a hipótese da saliency theory, discutida em Tarouco (2011), segundo a qual, tendo se reduzido as possibilidades competitivas da distinção ideológica, os partidos teriam passado a enfatizar diferentes questões da agenda pública, especializando-se em temas específicos, em substituição aos apelos tipicamente ideológicos.
} 
dos próprios políticos estejam captando o mesmo conceito: a posição política do partido, sua ideologia, com ou sem elementos de comportamento estratégico misturados ${ }^{16}$.

De qualquer forma, os resultados trazem a boa notícia de que, apesar da alardeada inconsistência ideológica dos partidos brasileiros, a sua classificação na dimensão esquerda-direita é reconhecida tanto pelos próprios políticos quanto pelos analistas. Isto significa que as classificações correntes são na maioria válidas e podem continuar sendo usadas nos estudos que, ainda hoje, procuram pelos efeitos da ideologia partidária sobre outras variáveis.

\section{Considerações Finais}

Dos dados analisados acima podemos concluir que o posicionamento dos partidos brasileiros no espaço bidimensional, a partir dos conteúdos dos documentos programáticos, não coincide diretamente com as classificações usuais. Entretanto, tais posicionamentos, longe de serem aleatórios, guardam alguma consistência seja com as mudanças de contexto, seja entre momentos diferentes dos mesmos partidos, seja ainda entre partidos aliados ou historicamente ligados.

Isto sugere que os textos dos manifestos contêm informações sobre as preferências dos partidos e sobre a identidade que eles pretendem projetar, que não devem ser ignoradas se pretendemos compreender o sistema partidário brasileiro. O que os partidos dizem de si mesmos nos seus programas permite identificá-los, se não em termos ideológicos, em termos de ênfases programáticas e, portanto de preferências políticas.

É preciso não perder de vista que não estamos analisando comportamentos dos partidos (que contêm aspectos estratégicos), mas preferências publicadas. $\mathrm{O}$ conteúdo dos programas que os partidos lançam cumpre o papel de expor à opinião pública (aos eleitores, aos partidos adversários e à imprensa) e a seus próprios militantes e filiados (formação de novos quadros internos, por exemplo juventude do partido) a imagem que os partidos pretendem construir de si próprios. O comportamento, por outro lado, seja nas votações parlamentares, seja nos governos, é consequência de diversos outros fatores, especialmente de questões relacionadas às coalizões de governo e às estratégias de oposição. Este ponto já foi enfatizado por Zucco Jr. (2009) e nos permite alertar para o fato de que o que estamos elaborando aqui é uma mensuração da variável preferência política dos partidos, que pode ser mobilizada como explicativa do seu comportamento.

Mesmo com estas dificuldades, a análise empreendida traz alguns achados dignos de nota. $\mathrm{O}$ primeiro é o fato de a análise bidimensional ter identificado a

\footnotetext{
${ }^{16}$ A comparação com resultados de análises de partidos de outros países já está em andamento em outro projeto e seus resultados serão importantes para avançar no entendimento do significado dos conteúdos programáticos no Brasil.
} 
ausência de partidos defendendo posições conservadoras de direita. A ausência de partidos posicionados no quadrante superior direito do gráfico 3 reforça a tese da "direita envergonhada" ao atestar um vácuo de representação (ao menos nos programas partidários) no campo liberal-conservador.

Outro aspecto a ser ressaltado encontra-se retratado na tabela 6. Os dados demonstram que análises realizadas por diferentes pesquisadores (a partir de diferentes abordagens) apresentam índices significativos de correlação. Este dado reforça a interpretação de que, apesar de suas mazelas, é possível identificar um padrão de atuação e de interação entre os principais partidos políticos brasileiros.

Gabriela da Silva Tarouco é Doutora em Ciência Política pelo IUPERJ e professora do Departamento de Ciência Política da Universidade Federal de Pernambuco. E-mail: gabrielat@uol.com.br

Rafael Machado Madeira Doutor em Ciência Política pela UFRGS e professor do Programa de Pós-graduação em Ciências Sociais da PUCRS. E-mail: rafaelmachadomadeira@gmail.com

\section{Referências}

BENOIT, Kenneth; LAVER, Michael. Party policy in modern democracies. New York: Routledge, 2006.

BUDGE, Ian; ROBERTSON David et. al. Ideology, strategy, and party change:

Spatial analyses of post-war election programmes in 19 democracies. New York: Cambridge University Press, 1987.

BUDGE, Ian. Experts Judgments of Party Policy Positions: Uses and limitations in political research. European Journal of Political Research, Essex, v. 37, n. 1, p. 103-113, jan. 2000.

BUDGE, Ian; KLINGEMANN, Hans-Dieter; VOLKENS, Andrea; BARA, Judith; TANNENBAUM, Eric (eds.). Mapping policy preferences: Estimates for parties, electors, and governments 1945-1998. New York: Oxford University Press, 2001.

COPPEDGE, Michael. A classification of Latin American political parties. Kellogg Institute Working Paper 244, 1997.

DOWNS, Anthony. Uma teoria econômica da democracia. São Paulo: Edusp, 1999.

ECCLESHALL, Robert; GEOGHEGAN, Vincent et. al. Political ideologies: an introduction. London: Routledge, 1994.

FERNANDES, Luis. Muito barulho por nada? O realinhamento políticoideológico nas eleições de 1994. Dados, Rio de Janeiro, v. 38, n. 1, p.107-144, 1995. 
GRAY, John. O Liberalismo. Lisboa: Editorial Estampa, 1988.

INGLEHART, Ronald. Culture Shift in advanced industrial society. Princeton: Princeton University Press, 1990.

JANDA, Keneth. Political Parties - a cross-national survey. New York: Macmillan Publishing Company, 1980.

KATZ, Richard S.; CROTTY, William. Handbook of Party Politics. London: Sage, 2006.

KLINGEMANN, Hans-Dieter; HOFFERBERT, Richard et. al. Parties, policies, and democracy. Boulder: Westview Press. 1994

KLINGEMANN, Hans-Dieter, VOLKENS, Andrea et. al. Mapping Policy Preferences II: Estimates for parties, electors, and governments in Eastern Europe, European Union and OECD 1990-2003. Oxford: Oxford University Press, 2006.

LAVER, Michael. Estimating the policy position of political actors. London: Routledge/ECPR, 2001.

LAVER, Michael; BUDGE, Ian. Party policy and government coalitions. New York: St. Martin's Press, 1992.

LEONI, Eduardo. Ideologia, democracia e comportamento parlamentar: a Câmara dos Deputados (1991-1998). Dados, Rio de Janeiro, v. 45, n. 3, p. 361386, 2002.

MADEIRA, Rafael M. Vinhos antigos em novas garrafas: a influência de exarenistas e ex-emedebistas no atual multipartidarismo brasileiro. 2006. $208 \mathrm{f}$. Tese (Doutorado em Ciência Política) - Programa de Pós-Graduação em Ciência Política, Universidade federal do Rio Grande do Sul, Porto Alegre, 2006.

MADEIRA, Rafael M.; TAROUCO, Gabriela. A "direita envergonhada" no Brasil: como partidos reinterpretam seus vínculos com o regime militar? In: ALACIP - Congresso Latino-americano de Ciência Política, 5., Buenos Aires, 2010.

MAINWARING, Scott; MENEGUELLO, Rachel et. al. Partidos conservadores no Brasil contemporâneo. São Paulo: Paz e Terra, 2000.

MAIR, Peter. Searching for the positions of political actors: a review of approaches and a critical evaluation of expert surveys. In: LAVER, Michael. (org.). Estimating the policy positions of political actors. London/New York: Routledge/ECPR, 2001. p. 10-30.

MIGUEL, Luis Felipe. Os partidos brasileiros e o eixo "esquerda-direita". In: KRAUSE, Silvana et. al. (orgs.). Coligações Partidárias na Nova Democracia Brasileira. São Paulo: Ed. Unesp, 2010.

NISBET, Robert. O Conservadorismo. Lisboa: Editorial Estampa, 1987.

QUINTON, Anthony. Conservatism. In: GOODIM, Robert; PETTIT, Philip; POGGE, Thomas (eds.). A companion to contemporary political philosophy. New Jersey: Blackwell Publishers, 1996. p. 285-311. 
POWER, Timothy. The political right in postauthoritarian Brazil: elites, institutions, and democratization. University Park: Pennsylvania State University Press, 2000.

. Centering Democracy? Ideological Cleavages and Convergence in the Brazilian Political Class. In: KINGSTONE, Peter; POWER, Timothy (orgs.). Democratic Brazil Revisited. Pittsburgh: University of Pittsburgh Press, 2008.

POWER, Timothy; ZUCCO, Cesar. O Congresso por ele mesmo. Belo Horizonte: Ed. UFMG, 2011.

. Replication data for: Brazilian Legislative Surveys. 2011. Disponível em: <http://hdl.handle.net/1902.1/14970>. Acessado em: 25 dez. 2011.

RYAN, Alan. Liberalism. In: GOODIM, Robert; PETTIT, Philip; POGGE, Thomas (eds.). A companion to contemporary political philosophy. New Jersey: Blackwell Publishers, 1996. p. 360-382.

SÁEZ, Manuel Alcántara; FREIDENBERG, Flavia. Partidos políticos na América Latina. Opinião Pública, Campinas, v. 8, n. 2, p. 137-157, oct. 2002.

SINGER, André. Esquerda e Direita no Eleitorado Brasileiro. São Paulo: Edusp/FAPESP, 2002.

TAROUCO, Gabriela; MADEIRA, Rafael M. Os partidos brasileiros segundo seus estudiosos: análise de um expert survey. In: CISO - Encontro Norte e Nordeste de Ciências Sociais, 15., Teresina, 2012a.

Left and Right in the Brazilian Party System. In: Congress of the Brazilian Studies Association, 11., University of Illinois at Urbana-Champaign, 2012b.

. Partidos, Programas e o Debate sobre Esquerda e Direita no Brasil. Revista de Sociologia e Política, Curitiba, v. 21, n. 45, p. 179-165, mar. 2013.

VOLKENS, Andrea. Manifesto research since 1979: from reliability to validity.

In: LAVER, Michael. Estimating the Policy Position of Political Actors.

London/New York: Routledge/ECPR, 2001. p. 33-49.

WIESEHOMEIER, Nina; BENOIT, Kenneth. Parties and Presidents in Latin America: Data from Expert Surveys in 18 Latin American Countries, 20062007. University of Konstanz: Trinity College Dublin, 2007.

. Presidents, Parties, and Policy Competition. The Journal of Politics, Statesboro, v. 71, n. 4, p. 1435-1447, oct. 2009.

ZUCCO, Cesar. Ideology or What? Legislative Behavior in Multiparty Presidential Settings. The Journal of Politics, Statesboro, v. 71, n. 3, p. 10767092, jul. 2009. 


\section{Apêndice}

Categorias para análise de conteúdo dos manifestos, adaptadas de Budge et. al. (2001), Volkens (2001) e Klingemann, Volkens et. al. (2006).

\begin{tabular}{|c|c|}
\hline Domínio 1 & Relações exteriores \\
\hline 101 & EUA positivo $^{17}$ \\
\hline 102 & EUA negativo \\
\hline 103 & Anti-Imperialismo \\
\hline 104 & Forças Armadas: positivo \\
\hline 105 & Forças Armadas: negativo \\
\hline 106 & Paz \\
\hline 107 & Internacionalismo: positivo \\
\hline 109 & Internacionalismo: negativo \\
\hline Domínio 2 & Liberdade e Democracia \\
\hline 201 & Liberdades e Direitos Humanos \\
\hline 202 & Democracia \\
\hline 203 & Constitucionalismo: positivo \\
\hline 204 & Constitucionalismo: negativo \\
\hline Domínio 3 & Sistema Político \\
\hline 301 & Descentralização \\
\hline 302 & Centralização \\
\hline 303 & Eficiência Governamental e Administrativa \\
\hline 304 & Corrupção \\
\hline 305 & Autoridade Política \\
\hline 306 & Instituições do sistema político $^{18}$ \\
\hline Domínio 4 & Economia \\
\hline 401 & Livre Iniciativa \\
\hline 402 & Incentivos \\
\hline 403 & Regulação do Mercado \\
\hline 404 & Planejamento Econômico \\
\hline 405 & Corporativismo \\
\hline 406 & Protecionismo: positivo \\
\hline 407 & Protecionismo: negativo \\
\hline
\end{tabular}

\footnotetext{
${ }^{17}$ A definição original de categorias 101 e 102 refere-se a um país com o qual o país do manifesto tem relações especiais. A escolha dos Estados Unidos é uma adaptação para a pesquisa sobre o Brasil.

${ }^{18}$ Esta categoria foi criada para acomodar referências recorrentes, em alguns manifestos, a reforma do sistema de governo.
} 


\begin{tabular}{|c|c|}
\hline 408 & Metas Econômicas \\
\hline 409 & Gerenciamento Keynesiano da demanda \\
\hline 410 & Produtividade \\
\hline 411 & Tecnologia e Infraestrutura \\
\hline 412 & Economia controlada \\
\hline 413 & Nacionalização \\
\hline 414 & Ortodoxia econômica \\
\hline 415 & Análise marxista \\
\hline 416 & Controle do crescimento \\
\hline Domínio 5 & Bem-estar e Qualidade de vida \\
\hline 501 & Proteção ambiental \\
\hline 502 & Cultura \\
\hline 503 & Justiça social \\
\hline 504 & Expansão do Welfare State \\
\hline 505 & Limitação do Welfare State \\
\hline 506 & Expansão da Educação \\
\hline 507 & Limitação da Educação \\
\hline Domínio 6 & Estrutura da sociedade \\
\hline 601 & Estilo nacional de vida e comportamento: positivo \\
\hline 602 & Estilo nacional de vida e comportamento: negativo \\
\hline 603 & Moralidade tradicional: positivo \\
\hline 604 & Moralidade tradicional: negativo \\
\hline 605 & Lei e Ordem \\
\hline 606 & Harmonia Social \\
\hline 607 & Multiculturalismo: positivo \\
\hline 608 & Multiculturalismo: negativo \\
\hline Domínio 7 & Grupos sociais \\
\hline 701 & Classes trabalhadoras: positivo \\
\hline 702 & Classes trabalhadoras: negativo \\
\hline 703 & Agricultura, agricultores \\
\hline 704 & Classe média e grupos profissionais \\
\hline 705 & Minorias desprivilegiadas \\
\hline 706 & Grupos demográficos não-econômicos \\
\hline 000 & $\begin{array}{l}\text { Nenhuma das Categorias Acima (frases que não se enquadram em } \\
\text { nenhuma das categorias anteriores: narrativas históricas, questões } \\
\text { internas do partido, frases com conteúdo muito vago, dados } \\
\text { estatísticos) }\end{array}$ \\
\hline
\end{tabular}

